\title{
Application of the SWAP model for sustainable agriculture in an arid region
}

\author{
B. Mostafazadeh-Fard ${ }^{1}$, H. Mansouri ${ }^{1}$, S. F. Mousavi ${ }^{1}$ \& M. Feizi ${ }^{2}$ \\ ${ }^{1}$ Irrigation Department, College of Agriculture, \\ Isfahan University of Technology, Isfahan, Iran \\ ${ }^{2}$ Isfahan Agricultural and Natural Resources Research Center, \\ Isfahan, Iran
}

\begin{abstract}
Iran is located in an arid and semi-arid region of the world with average annual precipitation of about $250 \mathrm{~mm}$. Due to lack of suitable water resources, many farmers are using saline river or groundwater for irrigation which causes gradual accumulation of salts in the soil. Salinity of soil and water resources is one of the major environmental factors limiting the productivity of agricultural lands and reduces land area under cultivation. For sustainable agricultural productions, appropriate irrigation management practices should be applied if the saline irrigation water is to be used for irrigation. The SWAP (soil-water-atmosphereplant) model is a physical-based model that can be used to simulate crop yield and soil salinity, among others. To collect field data to apply to this model as input and calibrate it, a field experiment planted with wheat was conducted on a silty clay loam soil, in the central part of Iran (the Rudasht region near Isfahan with an annual average precipitation of about $80 \mathrm{~mm}$ ), with three irrigation water salinity levels of 2, 8 and $12 \mathrm{dS} / \mathrm{m}$ with/without leaching levels of 4,19 and 32 percent with two different irrigation water managements, using factorial design with four replications. The results showed that the model is applicable in this arid region and has low sensitivity to input data of root distribution depth and irrigation water salinity and medium sensitivity to climate data, soil surface layer hydraulic characteristics, leaf area index and amount of irrigation. The model simulated wheat yield and the calibration coefficients were obtained. The results showed that the model could be used as an effective tool for sustainable agricultural production.
\end{abstract}

Keywords: SWAP model, wheat, yield, Iran. 


\section{Introduction}

During the last 3-4 decades, as the demand for agricultural productions increased the irrigated lands also increased by about $300 \%$. This has imposed a further increase in soil salinization and a relative decrease in crop yield [8]. Soil salinity is a major environmental factor limiting the productivity of agricultural lands. This problem is not only reducing the agricultural productivity, but is also putting far reaching impacts on the livelihood strategies of small farmers [11]. Use of saline water for irrigation is a subject of increasing interest because of the increasing water requirements for irrigation and the competition between urban, industrial and agricultural sectors and moreover because of the pressure for the disposal of drainage water through reuse [7].

It is estimated that up to $20 \%$ of irrigated lands in the world are affected somehow by different levels of salinity and sodium content. In Iran about $15 \%$ of lands, that is about 25 million ha, are suffering from this problem, including 320000 ha in Isfahan province [4]. Wheat is the most important and widely adapted cereal in Iran. Although Iran has recently been self-sufficient in its annual domestic demand for wheat, but salinity of soil and water resources, especially in arid and semi-arid regions of central parts of Iran, has effectively decreased wheat productivity. Overcoming of soil salinity and sodium content problems can be achieved by managing water resources, growing salt-tolerant plants, using leaching with appropriate drainage system and applying suitable models for irrigation and drainage management.

Knowledge of water flow and solute transport processes in the soil zone is essential to derive proper management conditions for plant growth and environmental protection in agricultural systems. Numerical models are widely used as helpful tools to gain insight in the processes occurring in these complex systems and to analyse optional management scenarios. One of these numerical models is SWAP (Soil-Water-Atmosphere-Plant). This model is a hydrological model which simulates transport of water, solutes and heat in variably saturated top soils in field scale [1, 12]. The model is the modified form of SWATR, SWATRE, and SWACROP models. Several researchers [2, 3, 13] have worked with this model to verify it or use it for different field conditions. For instance in India, SWAP was applied to formulate guidelines for irrigation planning in cotton-wheat crop rotation using saline ground water in alternation with canal water for sustainable crop production. The results showed that it was possible to use the saline water up to $14 \mathrm{dS} / \mathrm{m}$ alternatively with canal water for cottonwheat rotation in both sandy loam and loamy sand soils [9]. In another research using SWAP model on an approach to explore water management options in irrigated agriculture considering the constraints of water availability and the heterogeneity of irrigation system properties the results showed that under limited water condition, regional wheat yield could improve further if water and crop management practices are considered simultaneously and not independently [5]. In Netherlands, field data were collected to evaluate the SWAP model for nitrogen leaching [13]. 
Considering the fact that simulation models can be used as an effective tool for management of agricultural lands the objective of this study is to calibrate the SWAP model and determine its compatibility to simulate wheat yield for an arid region in central part of Iran.

\section{Materials and methods}

The Rudasht region (32.29/N, 52.10/E and elevation of about $1560 \mathrm{~m}$ above mean sea level) is located in southeast of Isfahan city, central part of Iran, with about 50000 ha of salt affected soils. In this area, because of high evapotranspiration demand, low annual rainfall of about $80 \mathrm{~mm}$, shallow groundwater table of about $3 \mathrm{~m}$, limitation of good quality river water and use of saline underground and drainage water for irrigation, the soils are losing their productivity continuously.

To achieve the objectives of this study, a typical salt affected soil of Rudasht region (silty clay loam texture) was chosen to plant wheat. Physical and chemical properties of soil were determined as shown in Tables 1 and 2, respectively. The chemical characteristics of irrigation water are shown in Table 3. Forty field experimental plots, each $5 \times 25 \mathrm{~m}$, were used to collect data. The winter wheat (Triticum aestivum L.) cultivar M-73-18 was planted in each plot. About $1.25 \mathrm{~kg}$ of N.P.K fertilizer was applied with irrigation water to each plot.

Table 1: $\quad$ Physical characteristics of soil.

\begin{tabular}{ccccccccc}
\hline $\begin{array}{c}\text { Depth } \\
(\mathbf{c m})\end{array}$ & $\begin{array}{c}\text { Clay } \\
(\mathbf{\%})\end{array}$ & $\begin{array}{c}\text { Silt } \\
\mathbf{( \% )}\end{array}$ & $\begin{array}{c}\text { Sand } \\
\mathbf{( \% )}\end{array}$ & Texture & $\begin{array}{c}\mathbf{F C} \\
\mathbf{( \% )}\end{array}$ & $\begin{array}{c}\mathbf{W P} \\
\mathbf{( \% )}\end{array}$ & $\begin{array}{c}\boldsymbol{\rho}_{b} \\
\left(\mathbf{g r} / \mathbf{c m}^{\mathbf{3}}\right)\end{array}$ & $\begin{array}{c}\mathbf{K} \\
(\mathbf{m} / \mathbf{d a y})\end{array}$ \\
\hline $0-30$ & 14 & 54 & 32 & Silty loam & 28 & 17 & 1.22 & 1.2 \\
$30-40$ & 46 & 44 & 10 & Silty clay & 27 & 17 & 1.10 & 1.4 \\
$40-65$ & 56 & 40 & 4 & Silty clay & 31 & 18 & 1.33 & 1.2 \\
$65-75$ & 56 & 40 & 4 & Silty clay & 32 & 19 & 1.82 & 2.0 \\
$75-90$ & 64 & 30 & 6 & Clay & 30 & 16 & 1.91 & 1.4 \\
\hline
\end{tabular}

Table 2: $\quad$ Chemical characteristics of soil.

\begin{tabular}{|c|c|c|c|c|c|c|c|c|c|}
\hline \multirow{2}{*}{$\begin{array}{c}\text { Depth } \\
\text { (cm) }\end{array}$} & \multirow{2}{*}{$\begin{array}{c}\mathrm{EC} \\
(\mathrm{dS} / \mathrm{m})\end{array}$} & \multicolumn{5}{|c|}{ Ions (meq/lit) } & \multirow{2}{*}{ pH } & \multirow{2}{*}{ ESP } & \multirow{2}{*}{ SAR } \\
\hline & & $\mathrm{HCO}_{3}$ & $\mathrm{Cl}$ & $\mathrm{SO}_{4}$ & $\mathrm{Ca}+\mathrm{Mg}$ & $\mathbf{N a}$ & & & \\
\hline $0-30$ & 6.8 & 3.6 & 40.3 & 33.7 & 43.6 & 35.0 & 7.6 & 19.8 & 7.5 \\
\hline $30-60$ & 6.2 & 3.5 & 30.0 & 35.4 & 41.4 & 28.5 & 7.6 & 21.1 & 6.3 \\
\hline $60-90$ & 6.5 & 3.5 & 30.0 & 40.0 & 39.0 & 36.5 & 7.7 & 31.1 & 8.3 \\
\hline
\end{tabular}

Table 3: $\quad$ Average values of irrigation water quality for the irrigation season.

\begin{tabular}{ccccccccc}
\hline \multirow{2}{*}{ Treat. } & Water & EC & \multicolumn{7}{c}{ Ions (meq/lit) } & \multirow{2}{*}{ SAR } \\
\cline { 4 - 8 } & source & $(\mathbf{d S} / \mathbf{m})$ & $\mathbf{H C O}_{3}$ & $\mathbf{C l}$ & $\mathbf{S O}_{4}$ & $\mathbf{C a}+\mathbf{M g}$ & $\mathbf{N a}$ & \\
\hline $\mathrm{Q}_{1}$ & River & 1.7 & 3.2 & 11.6 & 7.1 & 6.6 & 11.2 & 6.2 \\
$\mathrm{Q}_{2}$ & Well & 9.0 & 4.9 & 68.1 & 31.8 & 32.6 & 66.9 & 16.6 \\
$\mathrm{Q}_{3}$ & Drainage & 12.5 & 4.6 & 104.3 & 26.2 & 35.0 & 101.0 & 24.1 \\
\hline
\end{tabular}


The treatments consisted of three irrigation water salinity levels of 2, 8 and 12 $\mathrm{dS} / \mathrm{m}\left(\mathrm{Q}_{1}, \mathrm{Q}_{2}\right.$ and $\left.\mathrm{Q}_{3}\right)$ without leaching $\left(\mathrm{LR}_{0}\right)$ and with leaching $\left(\mathrm{LR}_{1}\right)$, including leaching levels of 4, 19 and 32 percent. Two different irrigation water managements were used. They include irrigating half of the plots with the above irrigation water salinity levels from the planting to the end of the growing season (GQ) and the other half with $\mathrm{EC}_{\mathrm{iw}}$ of $2 \mathrm{dS} / \mathrm{m}$ up to plant germination and thereafter applying the above irrigation water salinity levels (GU). The factorial design with completely randomized blocks with four replications was used.

The amount of irrigation water was based on cumulative evaporation from Class A pan, using pan coefficient of 0.81 . For all treatments, the irrigation intervals were based on about $82 \mathrm{~mm}$ evaporation from the pan. To account for rainfall, the precipitation data were taken from the weather station located nearby the experimental plots. Seven irrigations were applied during the growing season.

For each plot, soil samples were collected at the beginning, middle and end of the growing season. Soil samples were taken at depths of 0-30, 30-60 and 60-90 $\mathrm{cm}$ and were analyzed to determine bulk density, moisture content at field capacity, moisture content at wilting point, saturated hydraulic conductivity, saturation paste extract $\mathrm{EC}\left(\mathrm{EC}_{\mathrm{e}}\right), \mathrm{Ca}^{2+}+\mathrm{Mg}^{2+}, \mathrm{CO}_{3}{ }^{2-}, \mathrm{HCO}_{3}{ }^{-}, \mathrm{Cl}^{-}$and $\mathrm{Na}^{+}$using standard methods. The plant components were collected after harvest and were analyzed using standard methods. The leaf area index was calculated at five different crop growth stages during the growing season.

The SWAP model $[1,12]$ which was developed by researchers at both the DLO Winand Staring Centre and Wageningen Agricultural University was used to simulate yield for the field conditions using the collected data. Schematic of the SWAP model in relation to volume balance parameters for soil, plant and environment is shown in Fig. 1. The model contains five sub-models of METEO, CROP, SOIL, IRRIGATION, and TIMER. Each sub-model receives the related input data and analyzes it and sends the results to the main program. In submodel SOIL, SWAP employs Richards' equation for soil water movement. Due to its physical bases, the Richards' equation allows the use of soil hydraulic function data bases and simulation of all kind of scenario analysis. The soil hydraulic functions are described by the analytical expressions or by tabular values. Root water extraction at various soil depths is calculated from potential transpiration, root length density and possible reductions due to wet, dry, or saline conditions.

The input data such as soil surface layer hydraulic characteristics, maximum air temperature, leaf area index, root depth, irrigation water amount and irrigation water salinity were obtained and applied to the above five sub-models and the model was run. The sensitivity of the model to the input parameters was determined, the model was calibrated for the field conditions and the simulation results of yield for each treatment was compared with the field measurements and the statistical correlations were calculated.

Further information about the model, input data and the functions that are used in the model are given at internet address of www.alterra.nl/models/swap. 


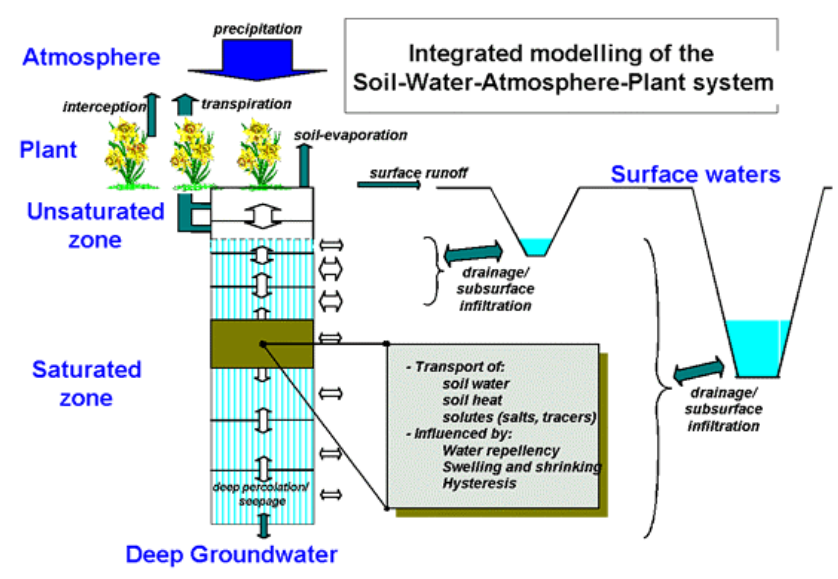

Figure 1: $\quad$ A schematized overview of the modelled system [12].

\section{Results and discussion}

\subsection{Sensitivity analyses}

Before applying a model, it is necessary to study the sensitivity of the model to the input parameters. The results of sensitivity analysis show the importance of each individual input parameter. After collecting the input data for the model, the sensitivity of the model to yield prediction due to the input parameters was studied. Soil, crop, irrigation and meteorological data were applied to the model and the Lane method [6] was used and the sensitivity of the model to the input data was determined. First, the model was run using the collected field data during the year 2005-2006 and the model output results were determined and the results were used as base data. Then, the model was run for the same input data again but the value of one of the input data was changed and set equal to +50 and - $50 \%$ of its original value. This process was repeated for all input values and the results were compared with the base data and the absolute differences were determined using the following equation [6]:

$$
D=\left|\frac{M-I}{I}\right| \times 100
$$

where $\mathrm{D}$ is the absolute difference between the output value and the base value, I is the base value, and $M$ is the output value. Then, based on Lane suggestions, the sensitivity of the model to each of the input data was determined as follows. For $\mathrm{D}=0$, model is not sensitive, for $0<\mathrm{D}<10$, the sensitivity of the model is low, for $10<\mathrm{D}<50$, the sensitivity of the model is medium, and for $\mathrm{D}>50$, the sensitivity of the model is high. The results of the sensitivity of the model to some of the input parameters are shown in Table 4. The results in Table 4 shows that the model has low sensitivity to the input data of root depth and irrigation 
water salinity and medium sensitivity to climatic data of solar radiation and maximum air temperature, soil surface layer hydraulic characteristics, leaf area index and amount of irrigation water. In Table $4, E_{a}$ is actual evaporation, $E_{p}$ is potential evaporation, $T_{a}$ is actual transpiration, $T_{p}$ is potential transpiration and $\mathrm{D}_{\mathrm{p}}$ is deep percolation.

Table 4: $\quad$ Values of the sensitivity of the model to input data.

\begin{tabular}{|c|c|c|c|c|c|c|c|c|}
\hline $\begin{array}{c}\text { Output Parameter } \\
\text { Input Parameter }\end{array}$ & $\begin{array}{c}\text { Soil } \\
\text { salinity }\end{array}$ & Yield & $\mathbf{E}_{\mathrm{a}}$ & $\mathbf{E}_{\mathrm{p}}$ & $\mathbf{T}_{\mathrm{a}}$ & $\mathbf{T}_{\mathrm{p}}$ & $\mathbf{D}_{\mathrm{p}}$ & Average \\
\hline $\begin{array}{c}\text { Soil surface layer } \\
\text { hydraulic } \\
\text { characteristics (-50\%) }\end{array}$ & 33 & 22 & 0 & 25 & 0 & 33 & 69 & 23 \\
\hline Solar radiation (+50\%) & 38 & 10 & 34 & 19 & 66 & 32 & 55 & 36 \\
\hline $\begin{array}{c}\text { Maximum temperature } \\
(-50 \%)\end{array}$ & 29 & 1 & 35 & 35 & 12 & 7 & 82 & 29 \\
\hline $\begin{array}{c}\text { Leaf area index (-50\%) } \\
\text { Leaf area index (+50\%) }\end{array}$ & 19 & 1 & 30 & 29 & 58 & 32 & 56 & 27 \\
\hline Root depth (-50\%) & 5 & 52 & 15 & 0 & 6 & 0 & 0 & 9 \\
\hline $\begin{array}{c}\text { Irrigation water } \\
\text { amount (-50\%) }\end{array}$ & 28 & 129 & 100 & 0 & 31 & 0 & 0 & 35 \\
\hline $\begin{array}{c}\text { Irrigation water } \\
\text { salinity (+50\%) }\end{array}$ & 2 & 48 & 7 & 0 & 3 & 0 & 0 & 7 \\
\hline
\end{tabular}

\subsection{Calibration}

Different methods can be used to calibrate the model, but the researchers [2] have suggested using the yield data to calibrate the model. In this study the model was calibrated based on wheat yield data. For calibration, the following steps were taken:

1- For different treatments, input data was given to the model and model was run and the simulation results of yield were obtained.

2- The simulation yield results were compared with the actual field yield results for each treatment.

3 - If the model simulation results were not close to the actual field results the crop sensitivity coefficient for yield $\left(\mathrm{K}_{\mathrm{y}}\right)$ was changed until the difference between the model simulation results and the actual field results become equal or less than $10 \%$.

The results of the above study for the determination of crop sensitivity coefficients for yield for model calibration are shown in Table 5.

\subsection{Statistical correlation}

After calibration of the model, the results of model simulation for yield and actual yield were used to determine the accuracy of the model. For this purpose, the statistical analysis was applied for yield and correlation coefficient, mean 
square root, absolute mean error and mean error were determined using standard methods (Table 6). The results in Table 6 show that the model is applicable to the study area which is an arid region and the model can be used as an effective tool for sustainable agricultural production. Since the model is applicable to the study area, then the model was used to simulate yield.

Table 5: $\quad$ Crop sensitivity coefficients for model calibration.

\begin{tabular}{|c|c|c|c|}
\hline \multirow{2}{*}{ Treatment } & \multicolumn{3}{|c|}{ Crop sensitivity coefficient $\left(K_{v}\right)$} \\
\hline & Beginning of season & Mid season & End of season \\
\hline $\mathbf{Q}_{1} \mathbf{G Q L R}_{0}$ & 0.33 & 1.27 & 0.28 \\
\hline $\mathbf{Q}_{1} \mathbf{G Q L R}_{1}$ & 0.30 & 1.15 & 0.25 \\
\hline $\mathbf{Q}_{2} \mathbf{G Q L R}_{0}$ & 0.90 & 3.45 & 0.75 \\
\hline $\mathbf{Q}_{2} \mathbf{G Q L R}_{1}$ & 0.87 & 3.34 & 0.73 \\
\hline $\mathbf{Q}_{2} \mathbf{G U L R}_{0}$ & 0.75 & 2.88 & 0.63 \\
\hline $\mathbf{Q}_{2}$ GULR $_{1}$ & 0.39 & 1.50 & 0.33 \\
\hline $\mathrm{Q}_{3} \mathrm{GQLR}_{0}$ & 1.31 & 5.00 & 1.09 \\
\hline $\mathrm{Q}_{3} \mathrm{GQLR}_{1}$ & 1.20 & 4.60 & 1.00 \\
\hline $\mathbf{Q}_{3} \mathbf{G U L R}_{0}$ & 0.81 & 3.11 & 0.68 \\
\hline $\mathbf{Q}_{3}$ GULR $_{1}$ & 0.69 & 2.65 & 0.58 \\
\hline
\end{tabular}

Table 6: $\quad$ Results of statistical analysis.

\begin{tabular}{|c|c|c|c|c|}
\hline Statistical indicator & $\mathbf{R}^{2}$ & RMSE & MAE & ME \\
\hline Indicator value & $\mathbf{0 . 6 8}$ & $\mathbf{0 . 7 1}$ & $\mathbf{0 . 3 9}$ & $\mathbf{- 0 . 1 9}$ \\
\hline
\end{tabular}

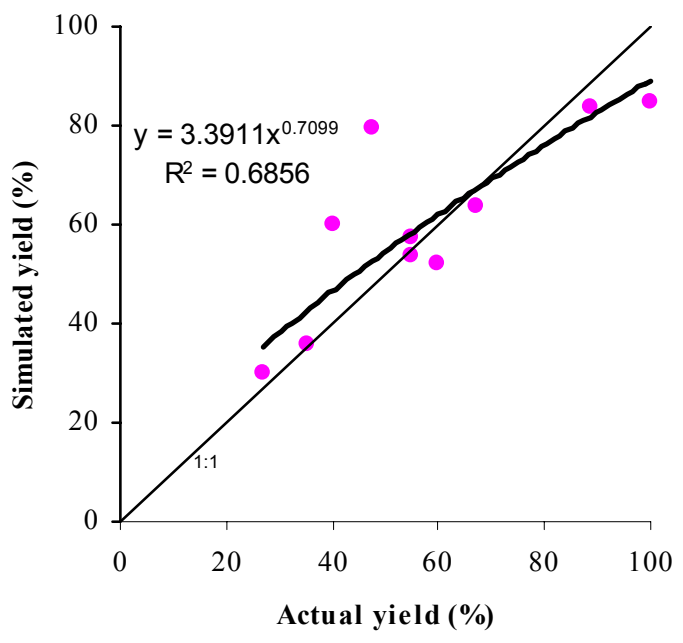

Figure 2: Comparison of the actual and simulated yield for different treatments. 


\subsection{Yield simulation}

After calibration and determination of the accuracy of the model, then it was used to simulate yield for the study area. In Fig. 2 the comparison between the model prediction and actual yield data for different treatments and also the equation of model simulation for yield is shown. The percentage shown in Fig. 2 is the ratio of yield of individual treatment to the yield of treatment that has the maximum yield. The results in Fig. 2 show there is a reasonable agreement between the model prediction and actual yield data. The results of other researchers $[2,5,10]$ for different crops and field conditions also show similar results.

\section{Conclusions}

For sustainable agricultural productions, appropriate irrigation management practices should be applied if the saline irrigation water is to be used for irrigation. The SWAP model can be used in such irrigated area to have better irrigation management for long term agricultural production. The model was calibrated for an arid region planted with wheat and irrigated with saline water and the accuracy of the model was determined. The simulation results of the model for yield showed that the SWAP model is applicable in arid region and could be used as an effective tool for better irrigation management.

\section{Acknowledgements}

This research was supported by Isfahan University of Technology and Isfahan Agricultural and Natural Resources Research Centre which is appreciated.

\section{References}

[1] Ashby, M., Dolman, A. J., Kabat, P., Moors, E. J. \& Ogink-Hendriks, M. J. SWAPS version 1.0. Technical reference manual. Technical document 42, Winand Staring Centre, Wageningen, 1996.

[2] Brandyle, T., Szaty, L., Gnatow, S. \& Tomasz, O. Examination of SWAP suitability to predict soil water conditions in a field peat-moorsh soil. Department of Water Resources, Wageningen Agricultural University. Report No. 69, 2005.

[3] Eitzinger, J., Trnka, M., Hösch, J., Žalud, Z. \& Dubrovský, M. Comparison of CERES, WOFOST and SWAP models in simulating soil water content during growing season under different soil conditions. J. of Ecological Modelling 171, pp. 223-246, 2004.

[4] Feizi, M. Considering the effect of water quality and quantity on desalinization of Isfahan Rudasht Soils. Technical Research Report, Isfahan Agricultural and Natural Resources Research Center, Isfahan, Iran. 8(1), pp. 16-34, 1993 
[5] Ines, A.V. M., Honda, K., Das Gupta, A., Droogers, P. \& Clemente, R. S. Combining remote sensing-simulation modelling and genetic algorithm optimization to explore water management options in irrigated agriculture. Agric. Water Manage. Available at: www.sciencedirect.com, 2006.

[6] Lane, J. W., \& Ferrira, V. A. Sensitivity in CREAMS: A field scale model for chemical runoff and erosion from agricultural management systems. Ed. w. g. Knisel, A model documentation. VSDA Conservation Res. Report No. 26. pp. 113-158, 1990.

[7] Ould Ahmed, B. A., Yamamoto, T., Rasiah, V., Inoue, M. \& Anyoji, H. The impact of saline water irrigation management options in a dune sand on available soil water and its salinity. Agric. Water Manage. 88, pp. 6372, 2007.

[8] Poustini, K. \& Siosemardeh, A. Ion distribution in wheat cultivars in response to salinity stress. J. of Field Crops Research 85, pp. 125-133, 2004.

[9] Singh, R. Simulation on Direct and Cyclic Use of Saline Waters For Sustaining Cotton-Wheat in a Semi-arid Area of North-West India. Agric. Water Manage. 66, pp. 153-162, 2004.

[10] Singh, R., Van dam, J. C. \& Feddes, R. A. Water productivity analysis of irrigated crops in Sirsa district, India. Agric. Water Manage. 82, pp. 253278, 2006.

[11] Tanwir, F., Saboor, A. \& Nawaz, N. Soil salinity and the livelihood strategies of small farmers: A case study in Faisalabad district, Punjab, Pakistan. Int. J. Agric. Biol. 5(4), pp. 440-441, 2003.

[12] Van Dam, J. C., Huygen, J., Wesseling, J. G., Feddes, R. A., Kabat, P., Van Walsum, P. E. V., Groenendijk, P. \& Van Diepen, C. A. Theory of SWAP version 2.0. Department of Water Resources, Wageningen Agricultural University. Report No. 71, 1997.

[13] Van der Salm, C., Van der Gon, H. D., Wieggers, R., Bleeker, A. \& Van den Toorn, A. The effect of afforestation on water recharge and nitrogen leaching in the Netherlands. J. of Forest Ecology and Management 221, pp. 170-182, 2005. 